\title{
Research Notes
}

\section{MANGO PULP EXTRACTING METHOD}

Mangos (Mangifera indica, L.) are widely used in Puerto Rico in the preparation of nectars, drinks, paste, and jams.

Information is available on the extraction of mango pulp by dilution with water, but efficient methods are lacking for the extraction of the undiluted pulp for processing pastes, jams and preserves. In the preparation of these products a mixture of the fruit pulp and sugar must be cooked to obtain a very high consistency. Prolonged heating is required to evaporate excess water from diluted pulp, resulting in higher cooking costs, lower yields and impaired quality products.

Canning of undiluted pulps for further use represents an additional advantage over canning of diluted pulps because less labor and fewer containers are required.

A mechanical method for extracting undiluted pulp from unpeeled mangos is described in this note. This method of pulp extraction makes possible a more complete utilization of mango crops by packing and storing the fruit pulps for remanufacturing high-quality products throughout the year.

Very limited information on the commercial extraction of mango pulps is found in the literature. Brekke $e t$ al. ${ }^{1}$ present a brief description of a method used with a paddle-type pulper to separate the pulp from Haden mangos during which the seeds were removed by hand. They also give information on the quality evaluation of heated and unheated purees extracted from peeled and unpeeled fruits. In their study, different heat treatments were applied to the extracted pulps rather than to the fruits. These mango pulps were preserved by freezing. Sánchez-Nieva et al. ${ }^{2}$ describe a batchwise pulp extraction method whereby diluted mango pulps are obtained by the action of a vertical blender on weighted quantities of fruit and water.

In the study herein reported, mangos of the Mayagüezano variety were used because of their relative abundance and their suitability for the preparation of high-quality nectars, ${ }^{3}$ preserves, jams, and paste. Freshly harvested mangos were inspected on a roller-type sorting table upon which water sprays removed dust and soil. Only ripe fruits with firm texture and

1 Brekke, J., Cavaletto, C., and Stafford, A. E., Mango puree processing, Iawaii Agr. Exp. Sta. Techuol. Progr. Rep. 1(iz, 19his.

z Sánchez-Nieva, F., Rodríguez, A. J., and Benero, J. R., Processing and camning mango nectars, $A$ gr. Exp. Sta. liniv. P.R., Bull. 148, 1959.

3 Peryam, I). R. and Pilgrim, F. J., Hedonic seale method of measuring food preferences, Food Techuol. 11 (9): 9-14, 1957. 
uniform yellow skin were selected. The sorted mangos were conveyed to a soaking tank with water containing 50 p.p.m. chlorine followed by a tap water rinse in a rod washer. The washed fruits were pretreated in two different ways prior to pulping. In one case the mangos were scalded at $200^{\circ} \mathrm{F}$. for 2.5 minutes in a continuous steam scalder and in the other, the

TABLE 1.-Dala on the pulping of Mayagüezano variely mangos afler fruil steaming and afler fruil peel-culting trealments

\begin{tabular}{lccccc}
\hline $\begin{array}{c}\text { Fruit treatment prior } \\
\text { to pulping }\end{array}$ & Run & Fruit & Pulp & $\begin{array}{c}\text { Pulp } \\
\text { extracted }\end{array}$ & $\begin{array}{c}\text { Pulp } \\
\text { reccvered }\end{array}$ \\
\hline & & Pounds & Pounds & Percent & Pcrcent \\
& 1 & 172.0 & 90.0 & 52.3 & 84.1 \\
Steaming & 2 & 200.0 & 108.0 & 54.0 & 86.9 \\
& 3 & 200.0 & 105.0 & 52.9 & 84.5 \\
& & & & & \\
Peel cuttiug & 1 & 168.0 & 83.0 & 49.5 & 79.4 \\
& 2 & 200.0 & 96.0 & 48.0 & 77.2 \\
& 3 & 200.0 & 94.0 & 47.0 & 75.6 \\
\hline
\end{tabular}

TAuL: 2.-Hedonic scale ralings of mango neclars manufactured from canned pulps oblainel after fruil steaming and peel-culling treatments and slored at $85^{\circ} \mathrm{F}$

\begin{tabular}{|c|c|c|c|c|c|}
\hline \multirow{3}{*}{ Fruit treatment } & \multirow{3}{*}{ Run } & \multicolumn{4}{|c|}{ Hedonic scale ratings* } \\
\hline & & \multicolumn{4}{|c|}{ Days in storage } \\
\hline & & 20 & 96 & 218 & 305 \\
\hline \multirow{3}{*}{ Steuming } & 1 & 7.2 & (i. 3 & 7.1 & - \\
\hline & 2 & 7.1 & 7.2 & (j. 1 & 7.2 \\
\hline & 3 & 7.2 & 7.6 & 7.3 & 7.4 \\
\hline \multirow{3}{*}{ Peel cutting } & 1 & 7.2 & 7.0 & ii.s & 7.3 \\
\hline & 2 & 6.5 & 7.0 & (i.s & 7.1 \\
\hline & 3 & 6.5 & 7.0 & (j.8 & - \\
\hline
\end{tabular}

* Hedonic ratings are based on a 9-point hedonic scale in which $9=$ "like extremely," $s=$ "like very much," 7 = "like moderately," $6=$ "like slightly," ete.

fruits were conveyed to a mechanical peel cutter consisting of a rotating drum with knives protruding $1 / 8$ inch from the surface of the drum.

$\Lambda$ fter pretreatment, the mangos were fed into a $E_{-}-Z$ Adjust Pulper ${ }^{4}$ in which nylon brushes revolving at 650 r.p.m. separated pulp from seeds and skin through a 0.060 -inch screen. The pulper performance was evalu-

4 Trade names are used in this paper solely for the purpose of providing sperific information. Mention of a trade name does not constitule a gutatule or waranty of the expuipment hy the Agrioultural lixperiment station of the liniversity of Puerto liaco or an endorsement over ot her equipment not mentioned. 
ated by comparing the pulp recoveries with the available pulp in the raw fruits.

Citric acid was added to the pulps to adjust the $\mathrm{pH}$ in the range of 3.5 to 3.8. The pulps were flash-pasteurized at $195^{\circ} \mathrm{F}$. in a Votator pasteurizer, packed in No. 10 cans and cooled in a tap water bath.

Samples were stored at $85^{\circ} \mathrm{F}$. for product evaluation. To ascertain the keeping quality of the canned pulps, nectars were prepared after four different storage periods and submitted to a tasting panel. The panelists were required to score the samples according to a 9-point hedonic scale. ${ }^{5}$

Pulp yields of mangos pretreated in the steam scalder and of mangos pretreated in the mechanical cutter are presented in table 1. The mangos were steamed at $200^{\circ} \mathrm{F}$. for 2.5 minutes because this was the highest temperature and the minimum holding time that could be obtained in the continuous scalder. Although care was taken, some broken seeds were encountered when the peel-cutting pretreatment was employed, while no breakage occurred when steam-pretreated. The pulps obtained were of an attractive bright yellow color and no discoloration or gelation was observed. The pulp extraction was in the range of 52.3 to 54.0 percent when the fruits were pretreated in the scalder and in the range of 47.0 to 49.5 percent when the fruits were pretreated in the peel cutter.

To obtain the pulper performance the pulp extractions were compared with the available pulp in the Mayagüezano variety, which averaged 62.? percent. The results presented in the last row of figures in table 1 indicate the recovery of pulp from steamed fruits was in the range of $\$ 4.1$ to 86.9 percent and from 75.6 to 79.4 percent for those treated mechanically. This demonstrates that steaming mangos prior to pulping produces a higher pulper performance and increases pulp recovery.

The results of the sensory evaluation of nectars prepared from each of six pulps kept under storage at $85^{\circ} \mathrm{F}$. are presented in table 2. Although hedonic ratings fluctuate between 6.1 and 7.8 for intermediate storage periods, at the end of 305 days of storage all nectars samples were scored above 7.0 (like moderately) thus indicating good quality. No perceptible change in the keeping quality was observed in pulps pretreated in the scalder or in the peel cutter when stored at $85^{\circ} \mathrm{F}$.

José R. Benero

Angel J. Rodriguez

Food Technology Laboralory

${ }^{5}$ Peryam, D. R. and Pilgrim, F. J., op. cit., p. 513. 